\title{
The EQ-i Profile of the Indonesians Compared to the Dutch: A Cross-Cultural Approach
}

\author{
Zahrasari L. Dewi', Magdalena S. Halim', Jan Derksen² \\ ${ }^{1}$ Department of Psychology, Atma Jaya Catholic University of Indonesia, Jakarta, Indonesia \\ ${ }^{2}$ Department of Clinical Psychology, Radboud University Nijmegen, Nijmegen, The Netherlands \\ Email: zahrasari.dewi@atmajaya.ac.id
}

Received 9 September 2015; accepted 16 October 2015; published 19 October 2015

Copyright (C) 2015 by authors and Scientific Research Publishing Inc.

This work is licensed under the Creative Commons Attribution International License (CC BY). http://creativecommons.org/licenses/by/4.0/

(c) (i) Open Access

\begin{abstract}
Indonesia, as a country which tends to be collectivistic, is characterized by a strong interrelationship and interdependency among the members of each social group. These characteristics make it more difficult for most Indonesians to be psychologically autonomous and to express their thoughts and emotions as extravert as the Dutch. This study attempts to portray the emotional intelligence (EI) competences of Indonesians as the fourth most populous country, compared to Dutch normative samples. By applying the EQ-i to 1274 Indonesians and 1455 Dutch participants, overall findings show, as predicted, that the level of EI of Indonesians is generally lower than that of the Dutch. The results reveal that there are significant differences for EQ total, five scales, and 15 sub-scales between the two groups. Based on the results, we see that the collectivistic tendency of the Indonesians as an Eastern society, to some extent, cannot optimally support the development of the EI competences, including interpersonal skill which is assumed to be higher in the Indonesian than in the Dutch. These results indicate that intervention programs in developing EI competences of Indonesian people can be helpful in developing society.
\end{abstract}

\section{Keywords}

Across Countries, Cross-Cultural, Dutch, Emotional Intelligence, Indonesian, Profiles

\section{Introduction}

Psychological differences between Eastern and Western societies are remarkable in a number of ways. The concepts of collectivism and individualism are traditionally used to characterize important ways in which societies 
differ. Eastern societies, well known as being more collectivistic, are usually contrasted with societies in the West, which are more individualistic. Indonesian people grow and develop in an Eastern cultural collectivistic heritage. Strong interrelationship, interdependent orientation, mutual dependency, social tolerance, harmony, more balanced exchange of support, and filial obligation are the dominant characteristics of Indonesians (Setiadi, Supratiknya, Lonner, \& Poortinga, 2004). For generations, Indonesians have valued the family as their foremost social environment, this being where they gain security as a member of a group. Strong bonds of affection among family members seem to lay a critical basis for the development of their emotional expression and social ability. Traditionally, Indonesians have described good emotions with reference to the interaction between parents and family members. In contrast to Indonesians, the Dutch internalize Western norms and values that generally emphasize personal independence and individualism.

Every psychological study on individual differences between Eastern and Western people should integrate these cultural differences. This diversity profoundly affects the development of human behavior and emotional competences such as self-appraisal, emotion regulation, self-regulation, achievement, motivation, competence, narcissism, and emotional closeness (Fjneman et al., 1996; Derksen, 2007; Van Dierendonck, Rodríguez-Carvajal, Moreno-Jiménez, Maria, \& Dijkstra, 2009; Li, Saklofske, Bowden, Yan, \& Fung, 2012). The theories of emotional intelligence (EI) have generated discussions in theoretical and empirical literatures over the past 20 years. The historical roots of the EI conceptualization can be found in the 19th century. Scientists have been studying the construct of EI as well as publishing scientific findings along the 20th and 21st centuries. At the beginning of the 1990s, for example, Mayer and Salovey published a series of articles on EI as well as carried out study and published the first EI ability measure. EI also emerged in a dramatic fashion following the publication of Emotional Intelligence by Daniel Goleman in 1995. The publication became a worldwide best-seller which was widely copied over several years and boosted the popularity of EI in workplace, educational, and health settings. A number of improvements in the concept of EI and a wide application of EI took place, along with the development of new measures for EI as well as the peer-reviewed research articles on this topic (BarOn \& Parker, 2000; Ciarrochi, Forgas, \& Mayer, 2001; Stough et al., 2009).

Identified as a non-cognitive intelligence, EI appears to support cognitive intelligence (IQ) in the development of an individual's emotion and cognitive capacities. With their psychometric independence, both IQ and EI are now known to complement each other in describing individual competence (BarOn \& Parker, 2000; Derksen, Kramer, \& Katzko, 2002; BarOn, 2004a; Stough, Saklofske, \& Parker, 2009). In theoretical models, and for purposes of measurement, EI is considered to be both ability and an expression of various personality characteristics. Salovey and Mayer's ability model explains EI as an intelligence or ability to identify, use, understand, and manage emotions. BarOn's mixed model includes traits and competences, and tries to explain the level of intelligence that represents a wide range of personality styles. This intelligence consists of the interrelation of emotional and social competences that contribute to how effectively individuals understand and express themselves, understand others and relate with them, and then cope with stress and daily demands (BarOn, 1997; BarOn \& Parker, 2000; BarOn, 2004a; Schulze \& Robert, 2005; Wood, Parker, \& Keefer, 2009; Stough et al., 2009).

\subsection{Why Is EI Important?}

We are inclined to agree with critiques of the term "emotional intelligence" which has not described in any definite way. Known as a non-academic intelligence, a non-cognitive intelligence, or practical intelligence, EI definitions encompass cognitive processes, such as social judgment, problem solving, and emotion perception as well as personality characteristics, such as extroversion, self-actualization, and motivation (BarOn \& Parker, 2000; Ciarrochi, Forgas, \& Mayer, 2001; Stough et al., 2009). However, we think that now we have some sense of what EI is, from the popular conception to the scientific inquiry. The historical development of EI construct this far and also its scientific and validated measures show EI as one of specific intelligences that contribute to the prediction of an individual's success in life (BarOn, 1997; BarOn \& Parker, 2000; BarOn, 2004a; Schulze \& Robert, 2005; Wood, Parker, \& Keefer, 2009; Stough et al., 2009). EI may be important in everyday life as it represents a level of intrapersonal skill; the self-orientation of a person, and interpersonal skills; the other-orientation of a person (BarOn, 1997; BarOn \& Parker, 2000). We think that the optimal and balance maturity of the two orientations is important for any individual as, by nature, a social creature. It seems reasonable to assume that individuals who are poor in dealing with stress and emotions will have weak relationship, poor health 
condition, and less success in study and work. If individuals cannot understand what other people feel or have great difficulty in doing so, they may have problems with building a meaningful and successful social interaction or to maintain a close relationship with friends. In contrast, individuals who cope with life stress adequately, manage their own life well, fully accept their own strengths and weaknesses, and establish good relations with others will have success in life (BarOn \& Parker, 2000; Ciarrochi, Forgas, \& Mayer, 2001; Stough et al., 2009). Different from IQ, EI has a more practical meaning as it is a fluid and a trainable kind of intelligence (BarOn \& Parker, 2000; Stough et al., 2009). Accordingly, we can expect that through the development of EI the underdeveloped Indonesian society might profit in a variety of ways. Our expectation is based on several observations along time. First, Indonesia is a developing country which still needs, at least to some extent, to be developed in terms of its individuals' potentials. A preliminary study on Indonesians' personality characteristics using the revised NEO personality inventory, for example, has previously described the Indonesians' personality factors (Halim, Derksen, \& Staak, 2004). We expect that our study will contribute to other findings in the aim to continually improve the Indonesians' capabilities. Developing the emotional capabilities of the people means on a societal level contributing to the advancement of social and cultural structures and patterns. It is logical because the development of a country depends in many ways on the quality of its people. We consider that EI is an individual's behavior style that can be significantly developed through creating intervention programs using a portrait of EI profile as a reference. Second, there are currently many social phenomena in Indonesia, including a higher prevalence rate of physical and mental health problems of young to middle-aged adults (Depkes RI, 2006; WHO, 2013; CDC-Atlanta, 2014). Research in EI potentially contributes to these problems, not only through a description of EI, but also through a more practical application and direct action. Third, many previous studies of EI in the West that have been conducted in various life settings, such as educational, workplace, and health intended to contribute to improvements. We image a wide application of EI in many life settings in Indonesia, both for preventive purposes that focus on developing the individuals' potential and for curative purposes that focus on helping individuals to regain their health and quality of life. For example, assessment of EI in an industrial organization can be integrated with other assessments, such as IQ level and achievement tests, in developing Indonesian workers. In educational context, for example, EI can be used to create a social and emotional learning program for students in supporting their academic performance. Furthermore, EI can be used to create training programs to educate Indonesian adults, either as parents or teachers or both, in developing the social and emotional and emotional competences of their younger generation in family, educational, and also social community settings.

The explanation of EI in the context of culture requires the utmost care. Societal norms are specific to each cultural group and make a valuable contribution to the development of emotional expression and social behavior among group members (Alisjahbana, 1989; Matsumoto, 1984; Berry, Poortinga, Segall, \& Dasen, 2002; Koentjaraningrat, 2002; Schulze \& Robert, 2005; Wood et al., 2009). EI evaluation in Indonesians, for example, might be different from that of the Dutch. The Netherlands is one country that can represent Western society where many studies on EI have been done previously. Authors of previous studies have stressed the need to investigate how EI skills differ between different societies (Parker et al., 2005; Ekermans, Saklofske, Austin, \& Stough, 2011). Applying EI self-report in a community can be also regarded as a more practical and promising method because the process of collecting data about behavioral styles and attitudes can be done more effectively and efficiently. As a prerequisite, the psychometric integrity of the self-report should, of course, be really well-established and reliable (Kitayama \& Markus, 1994).

\subsection{The Present Study}

This study aims to see whether there are any significant differences in overall scores on the EQ-i between Indonesian and Dutch samples. The cross-group comparison works on the assumption that the Dutch were expected to gain a higher score than the Indonesians for total EQ. More specifically, we expected the Dutch to score significantly higher in intrapersonal, adaptability, stress management, and general mood competences than the Indonesians, who were expected to score higher in interpersonal competence (Derksen, 2007). The independent orientation of the Dutch and their individualistic and narcissistic tendency, developed during centuries of individualization, possibly have a considerable impact on their ability to know their own emotional, personal, social, and self-defense competences better than the Indonesians. In contrast, the Indonesians, who are more collectivistic, are probably more skillful in interpersonal relationships than the Dutch. 
Another aim of this study was to examine gender differences in response to the EQ-i and how cultural differences affect the development of EI in men and women. To some extent, the social and cultural environment will contribute to prevailing gender stereotypes in a society which are controlling and promoting the acceptable gendered behavior from early age to adolescent and adult age (Gardiner \& Kosmitzki, 2005). Previous studies on Dutch male and female nurses, for example, found that there were different EI profiles in men and women (Gerits, Derksen, \& Verbruggen, 2004; Gerits, Derksen, Verbruggen, \& Katzko, 2005; Dusseldorp, van Meijel, \& Derksen, 2011). Supported by previous finding on North Americans (BarOn, 2004b), we hypothesize that the significant main effect of gender differences in Indonesian and Dutch normative samples as well as their possible interaction effect with country differences. More specifically, we expect that women, both Indonesian and Dutch, would be shown to be significantly stronger in interpersonal competence than men. In contrast, men would be significantly higher in intrapersonal, adaptability, stress management, and general mood competences than women. These assumptions are supported by the previous study that found stronger interpersonal skills, greater awareness of others' feelings, and more empathy in women than in men (BarOn \& Parker, 2000). A gender role that places women as a key person for almost all domestic duties makes it possible for most women to become more sensitive and aware of others' needs and feelings. It is possible for most Indonesian women to internalize traditional values and accepted behavior especially in both traditional and modern counterpart.

\section{Method}

\subsection{Participants}

Indonesian $(N=1274$; Mean age $=40.84 ; S D=11.11 ; 47.3 \%$ Men $)$ and Dutch $(N=1455$; Mean age $=51.21$; $S D=13.25 ; 57.7 \%$ Men) adults participated in this study. The Indonesian samples were selected from several cities: Jakarta, Bandung, Yogyakarta, Surakarta, Medan, and Padang. The Dutch samples were selected from cities in the Netherlands in such a way that the whole sample is representative for the Dutch population. Table 1 shows the distribution of the two countries' samples based on gender and age groups.

\subsection{Measure}

The EQ-i 133-items (BarOn, 2004b) provide 117 items of total measure of EI and scores on the five composites scales (15 sub-scales). First, intrapersonal scale consists of self-regard, emotional self-awareness, assertiveness, independence, and self-actualization sub-scales. Second, interpersonal scales consists of empathy, social responsibility, and interpersonal relationship sub-scales. Third, adaptability scale consists of reality testing, flexibility, and problem solving sub-scales. Fourth, stress management scale consists of stress tolerance and impulse control sub-scales. Fifth, general mood scale consists of happiness and optimism sub-scales. The other 15 items measure the positive impression (PI) and negative impression (NI) scores. The final item is a continuation of the instruction (item 133). Items are scored on a five point Likert scale. The EQ-i was adapted for Dutch and Indonesian according to the scientific standards available in this domain.

We focused on the analyses of the EQ total, scales, and sub-scales of the EQ-i. Indonesian and Dutch versions were applied to each group. Internal consistency reliability, calculated by Cronbach's alpha coefficients for the total EQ and each scale and sub-scales across samples, yielded a lower result for the Indonesians than for the

Table 1. Summary of demographic data across indonesian and dutch samples.

\begin{tabular}{ccc}
\hline Participants & Indonesian & Dutch \\
\hline Total Number & 1274 & 1455 \\
Men & 602 & 839 \\
Women & 672 & 616 \\
Age & & \\
$30-39$ & 755 & 335 \\
$40-49$ & 201 & 382 \\
50 \& Above & 318 & 738 \\
\hline
\end{tabular}


Dutch. Both groups, however, show good reliability, with alpha coefficients of total EQ of 0.96 and 0.94 for Indonesians and Dutch respectively. For Indonesians, the alpha coefficients of EQ scales and sub-scales ranged from 0.57 - 0.87 while for the Dutch the range was $0.71-0.92$.

\subsection{Data Analytic Strategy}

Descriptive analysis was performed to show a general description of Indonesian and Dutch normative data. To maximize the comparability of EI profiles across the countries, the total, scales, and sub-scales EQ raw scores for each country were converted to standardize $T$-scores. Following an earlier study (BarOn, 2004b), we calculated the standard $T$-score by using the $100+15$ (z-score). We transformed the Indonesian raw score into the standard $T$-score by using the Dutch norm as a reference point. We did this because the Netherlands is one of the major Western countries where the EQ-i has already been developed. We expected to find more reliable results in the Eastern-Western comparisons by using the one standardized score. This procedure is intended to maximize the goal of this study of comparing the EQ-i between Indonesian and Dutch samples.

To complete the cross-group comparison analyses, the $t$-test and one-way analysis of variance (ANOVA) were also conducted. Further, the 2-way ANOVA was then tested to see the main effect of gender and country differences, as well as possible significant interactions, in EQ total, scales, and sub scales within each groups. This study applied Cohen's effect size criteria commonly used across many fields. In general, $\leq 0.20$ is a small effect size, 0.50 is a moderate effect size, and $\geq 0.80$ is a large effect size (Cohen, 1988).

\section{Result}

\subsection{Descriptive Analysis}

Table 2 and Table 3 show the mean scores and standard deviation of the EQ-i for the Indonesian and Dutch groups. The result yielded a higher score for the Dutch than for the Indonesians in the total EQ, scales, and subscales. The distribution of mean $T$-scores of the Indonesian compared to the Dutch norm, illustrated in Figure 1, showed the lower scores on total EQ, scales, and sub-scales for Indonesians. The result showed a potential effect of the individualistic in the Dutch group and collectivistic in the Indonesian group on the ability to understand their own emotions as well as others, and to build interpersonal relationships.

\subsection{Comparison across Groups}

The independent-sample $t$-test shows the differences in the mean scores of total EQ, scales, and sub-scales between Indonesian and Dutch samples (see Table 2 and Table 3).

The score for the Dutch group, as well as illustrated in the profile of the $T$-score, was significantly higher than for the Indonesian. For example, the total EQ was higher in the Dutch $(M=443.13, S D=39.27)$ than in the Indonesian $(M=396.27, S D=49.22)$, a statistically significant difference, $t(2727)=27.63, p=.00, d=1.06$. It is hoped that the result can more clearly illustrate the contribution of Eastern and Western cultural values in the development of emotional and social behavior. Cultural differences, especially between the Indonesian and the Dutch, produce significantly different scores on the EQ competences.

Table 2. Summary of descriptive analysis and independent t-test the EQ total and scales across Indonesian and Dutch samples.

\begin{tabular}{|c|c|c|c|c|c|}
\hline \multirow[b]{2}{*}{ EQ total \& scales } & \multicolumn{2}{|c|}{ Mean $(S D)$} & \multirow[b]{2}{*}{$t(2727)$} & \multirow{2}{*}{\multicolumn{2}{|c|}{$\begin{array}{c}\text { Effect size } \\
(d)\end{array}$}} \\
\hline & Indonesian $(N=1274)$ & Dutch $(N=1455)$ & & & \\
\hline Intrapersonal & 133.69 (18.33) & 150.22 (17.94) & 23.77 & 0.00 & 0.91 \\
\hline Interpersonal & $86.68(10.16)$ & $93.72(9.26)$ & 18.95 & 0.00 & 0.73 \\
\hline Adaptability & 85.60 (11.49) & $95.86(9.50)$ & 25.54 & 0.00 & 0.98 \\
\hline Stress management & $57.33(9.74)$ & $65.36(8.18)$ & 23.41 & 0.00 & 0.90 \\
\hline General mood & $61.78(8.17)$ & $67.39(7.56)$ & 18.62 & 0.00 & 0.71 \\
\hline EQ total & 396.27 (49.22) & 443.13 (39.27) & 27.63 & 0.00 & 1.06 \\
\hline
\end{tabular}


Table 3. Summary of descriptive analysis and Independent t-test the EQ sub-scales across Indonesian and Dutch samples.

\begin{tabular}{cccccc}
\hline & \multicolumn{2}{c}{ Mean $(S D)$} & & Effect size \\
\hline EQ sub-scales & Indonesian $(N=1274)$ & Dutch $(N=1455)$ & $t(2727)$ & $p$ & $(d)$ \\
\hline ES & $26.87(4.11)$ & $27.91(4.76)$ & 6.11 & 0.00 & 0.23 \\
AS & $22.12(3.55)$ & $24.91(4.17)$ & 18.71 & 0.00 & 0.72 \\
SR & $32.67(4.96)$ & $35.35(5.46)$ & 13.34 & 0.00 & 0.51 \\
SA & $30.91(4.82)$ & $35.75(4.24)$ & 27.91 & 0.00 & 1.07 \\
IN & $21.12(5.59)$ & $26.30(4.43)$ & 26.96 & 0.00 & 1.03 \\
EM & $28.81(3.95)$ & $31.40(3.98)$ & 16.99 & 0.00 & 0.65 \\
RE & $36.52(4.64)$ & $40.12(4.25)$ & 21.16 & 0.00 & 0.81 \\
IR & $39.78(5.74)$ & $41.89(5.39)$ & 9.93 & 0.00 & 0.38 \\
PS & $28.81(3.62)$ & $29.68(3.86)$ & 6.07 & 0.00 & 0.23 \\
RT & $31.82(5.81)$ & $38.56(4.53)$ & 33.95 & 0.00 & 1.30 \\
FL & $24.97(4.72)$ & $27.62(4.30)$ & 15.39 & 0.00 & 0.59 \\
ST & $30.13(4.42)$ & $32.26(5.01)$ & 11.69 & 0.00 & 0.45 \\
IC & $27.21(7.21)$ & $33.11(5.38)$ & 24.41 & 0.00 & 0.94 \\
HA & $31.21(5.98)$ & $36.88(4.82)$ & 27.42 & 0.00 & 1.05 \\
OP & $30.57(3.96)$ & $30.51(3.84)$ & 0.41 & 0.68 & 0.02 \\
\hline
\end{tabular}

Note: EQ-i Abbreviations: ES = Emotional Self-Awareness; AS = Assertiveness; SR = Self-Regard; SA = Self-Actualization; IN = Independence; $\mathrm{EM}$ = Empathy; IR = Interpersonal Relationship; RE = Social Responsibility; PS = Problem Solving; RT = Reality Testing; FL = Flexibility; ST = Stress Tolerance; IC = Impulse Control; HA = Happiness; OP = Optimism (BarOn, 2004b).

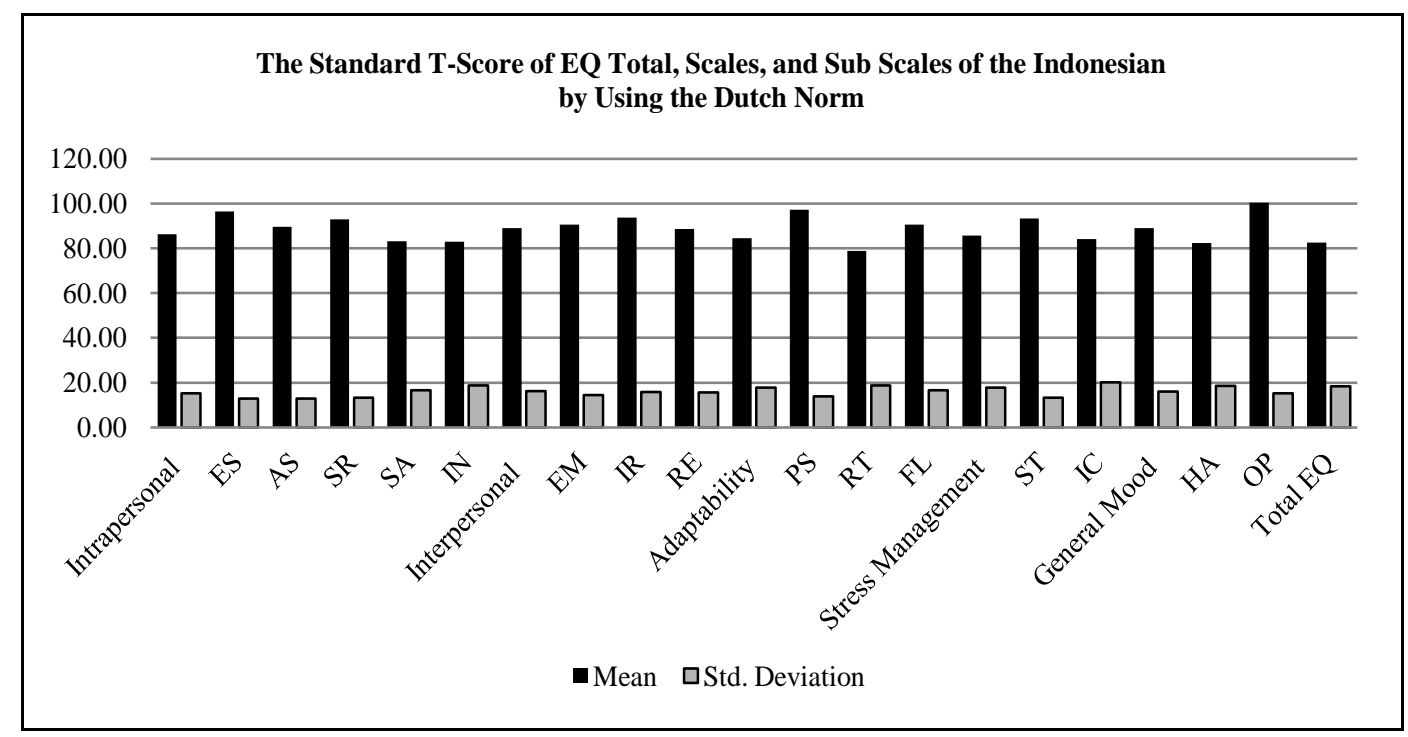

Figure 1. The distribution of mean $T$-scores and standard deviation of EQ total, scales, and sub scales of Indonesian normative sample compared to the Dutch Norm. Note: EQ-i Abbreviations: ES = Emotional Self-Awareness; AS = Assertiveness; SR = Self-Regard; SA = Self-Actualization; IN = Independence; EM = Empathy; IR = Interpersonal Relationship; RE = Social Responsibility; PS = Problem Solving; RT = Reality Testing; FL = Flexibility; ST = Stress Tolerance; $\mathrm{IC}=$ Impulse Control; HA = Happiness; OP = Optimism (BarOn, 2004b). 
According to the importance of gender difference on the EI development, the independent-sample $t$-test was also conducted to examine the differences of total EQ, scales, and sub scales between men and women in the group of each country. The results show that the Indonesian women $(\mathrm{N}=671, M=403.23, S D=49.86)$ reach a significantly higher score for total $\mathrm{EQ}$ than Indonesian men $(\mathrm{N}=602, M=388.36, S D=47.19), t(1271)=5.45$, $p=.00, d=0.31$ as well as that for all five scales and most of sub scales. The Indonesian men and women obtain a relatively equal score for empathy, social responsibility, problem solving, and optimism. The Cohen's $d$ effect size ranged from 0.14 - 0.32. Whereas, the Dutch women $(\mathrm{N}=616, M=96.35, S D=8.84)$ reach significantly higher level of interpersonal competence than the Dutch men $(\mathrm{N}=840, M=91.82, S D=9.11), t(1454)=9.49, p$ $=.00, d=0.50$ as well as that for emotional self-awareness, empathy, social responsibility, and interpersonal relationship. The Cohen's $d$ effect size ranged from 0.13 - 0.51 .

A one-way between subjects ANOVA was conducted to investigate differences in the EQ scores among four groups of samples based on country and gender groups. The result shows that there are significant differences for total EQ, scales, and sub-scales among Indonesian men, Indonesian women, Dutch men, and Dutch women with the $\eta^{2}$ effect size ranged from $0.01-0.31$ (see Table 4 and Table 5). Further analyses by using Tukey's test

Table 4. Summary of one-way ANOVA of the EQ total and scales across countries and sex groups.

\begin{tabular}{|c|c|c|c|c|c|c|c|}
\hline \multicolumn{8}{|c|}{ Mean $(S D)$} \\
\hline EQ Total \& Scales & Indonesian Men & Indonesian Women & Dutch Men & Dutch Women & & & Effect Size \\
\hline & $(N=602)$ & $(N=672)$ & $(N=839)$ & $(N=616)$ & $F(3,2725)$ & $p$ & $\left(\eta^{2}\right)$ \\
\hline Intrapersonal & $130.65(17.92)$ & $136.37(18.25)$ & $151.21(17.46)$ & $148.91(18.52)$ & $204.49 *$ & 0.00 & 0.18 \\
\hline Interpersonal & $85.66(9.41)$ & $87.56(10.68)$ & $91.82(9.11)$ & $96.35(8.84)$ & $155.71^{*}$ & 0.00 & 0.15 \\
\hline Adaptability & 83.95 (11.13) & 87.05 (11.60) & $96.41(9.40)$ & $95.14(9.60)$ & $232.25 *$ & 0.00 & 0.20 \\
\hline Stress Management & $55.81(9.53)$ & $58.67(9.71)$ & $66.43(8.04)$ & $63.93(8.16)$ & $208.40 *$ & 0.00 & 0.19 \\
\hline General Mood & $60.83(7.76)$ & $62.61(8.43)$ & $67.57(7.32)$ & $67.15(7.88)$ & $122.73 *$ & 0.00 & 0.12 \\
\hline Total EQ & 388.36 (47.19) & 403.23 (49.86) & $443.90(38.57)$ & $442.15(40.23)$ & $271.67 *$ & 0.00 & 0.23 \\
\hline
\end{tabular}

*. The mean difference is significant at the 0.05 level.

Table 5. Summary of one-way ANOVA of the EQ sub-scales across countries and sex groups.

\begin{tabular}{cccccccc}
\hline & \multicolumn{2}{c}{ Mean $(S D)$} & & & \\
EQ Sub-Scales & Indonesian Men & Indonesian Women & Dutch Men & Dutch Women & & Effect Size \\
\hline & $(N=602)$ & $(N=672)$ & $(N=839)$ & $(N=616)$ & $F(3,2725)$ & $p$ & $\left(\eta^{2}\right)$ \\
\hline ES & $26.26(3.90)$ & $27.40(4.21)$ & $27.36(4.72)$ & $28.68(4.72)$ & $30.45^{*}$ & 0.00 & 0.03 \\
AS & $21.77(3.49)$ & $22.43(3.58)$ & $25.14(4.21)$ & $24.60(4.09)$ & $123.01^{*}$ & 0.00 & 0.12 \\
SR & $32.24(4.72)$ & $33.04(5.13)$ & $36.12(5.02)$ & $34.31(5.87)$ & $77.77^{*}$ & 0.00 & 0.08 \\
SA & $30.19(4.68)$ & $31.56(4.84)$ & $35.70(4.26)$ & $35.83(4.21)$ & $273.15^{*}$ & 0.00 & 0.23 \\
IN & $20.19(5.84)$ & $21.95(5.22)$ & $26.88(4.27)$ & $25.50(4.51)$ & $271.12^{*}$ & 0.00 & 0.23 \\
EM & $28.82(3.87)$ & $28.80(4.03)$ & $30.55(3.95)$ & $32.54(3.73)$ & $130.35^{*}$ & 0.00 & 0.13 \\
RE & $36.32(4.39)$ & $36.68(4.84)$ & $39.22(4.27)$ & $41.35(3.90)$ & $183.73^{*}$ & 0.00 & 0.17 \\
IR & $39.06(5.25)$ & $40.39(6.07)$ & $41.18(5.41)$ & $42.88(5.24)$ & $51.51^{*}$ & 0.00 & 0.05 \\
PS & $28.74(3.45)$ & $28.87(3.75)$ & $30.25(3.85)$ & $28.92(3.76)$ & $28.05^{*}$ & 0.00 & 0.03 \\
RT & $30.88(5.70)$ & $32.66(5.78)$ & $38.48(4.44)$ & $38.67(4.64)$ & $403.67^{*}$ & 0.00 & 0.31 \\
FL & $24.34(4.69)$ & $25.52(4.69)$ & $27.68(4.38)$ & $27.55(4.19)$ & $87.32^{*}$ & 0.00 & 0.09 \\
ST & $29.80(4.30)$ & $30.41(4.50)$ & $33.19(4.70)$ & $30.99(5.16)$ & $75.28^{*}$ & 0.00 & 0.08 \\
IC & $26.01(7.27)$ & $28.26(6.99)$ & $33.24(5.41)$ & $32.93(5.34)$ & $216.52^{*}$ & 0.00 & 0.19 \\
HA & $30.21(5.83)$ & $32.09(5.98)$ & $36.72(4.79)$ & $37.10(4.84)$ & $268.64^{*}$ & 0.00 & 0.23 \\
OP & $30.61(3.76)$ & $30.52(4.13)$ & $30.85(3.60)$ & $30.04(4.10)$ & $5.21^{*}$ & 0.00 & 0.01 \\
\hline
\end{tabular}

*. The mean difference is significant at the .05 level. Note: EQ-i Abbreviations: ES = Emotional Self-Awareness; AS = Assertiveness; SR = SelfRegard; SA = Self-Actualization; IN = Independence; EM = Empathy; IR = Interpersonal Relationship; RE = Social Responsibility; PS = Problem Solving; RT = Reality Testing; FL = Flexibility; ST = Stress Tolerance; IC = Impulse Control; HA = Happiness; OP = Optimism (BarOn, 2004b). 
also indicated that the mean score for total EQ for Dutch men $(M=443.90, S D=38.57)$ was significantly higher than for Indonesian women $(M=403.23, S D=49.86)$, effect size $d=0.91$ and Indonesian men $(M=388.36, S D=$ 47.19), effect size $d=1.29$ as well as for all scales and sub-scales. The test also found that the mean score for Dutch women was significantly higher than for Indonesian women and Indonesian men for total EQ as well as all scales and sub-scales. Individualistic values of the Dutch group, as hypothesized, have a greater positive impact on the Dutch men than on the women, while collectivistic values seem to have a more positive impact on Indonesian women than men. We further see that the gender differences, as expected, also make a significant contribution to the development of EI competences. This is more specifically related to differences in gender role resulting from cultural values.

The 2-way ANOVA was also conducted to see the effect of country and gender, and their interaction with EI competences as the dependent variable. Country appeared as a significant main effect for the total EQ, all scales, and sub-scales, except optimism. Gender also appeared as a significant main effect on total EQ, scales and subscales, except stress management, assertiveness, and independence. The interaction effect of country and gender appeared significant for total EQ, scales, and sub-scales, except emotional self-awareness and interpesonal relationship (see Table 6 and Table 7). For example, the main effect of country on total EQ yielded an $F$ ratio of $\left[F(1,2725)=772.75, p=.00, \eta^{2}=0.22\right]$ with the Dutch scoring higher than Indonesians, while the interaction effect yielded an $F$ ratio of $\left[F(1,2725)=24.24, p=.00, \eta^{2}=0.01\right]$. The effect size for country and gender main effects and the interaction effect are mostly small with $\eta^{2}$ between $0.00-0.02$.

\section{Discussion}

The Indonesian group, as predicted, scored significantly lower than the Dutch group on the total EQ, five scales, and 15 sub-scales with the apparent moderate to large effect size (see tables). The Indonesians who were expected to score higher on interpersonal competence was not proven here. The independence orientation of the Dutch has a potential influence not only on their ability to know their own emotional and personal capabilities, but also on their skill in building interpersonal relationship. This result comes up with the possibility for Western society, which is assumed to be more individualistic, to show good social behavior and interpersonal relationships which were assumed stronger in Eastern society.

Eastern society, which tends to be more collectivistic, was potentially characterized with a relational self. They grow and develop in the emotional and material interdependence family model where the members of a family usually rely on each other, especially in case of sickness and old age security (Berry et al., 2002). We think that the lower scores of the Indonesians than of the Dutch for intrapersonal and interpersonal competences, for example, probably represent this kind of self within the Indonesians. Most Indonesian people tend to assign priority to the role of authority figures as decision makers, dominant, respected, admired, and relied upon. Values of civility, manners, respect, and compliance with authority figures; such as: parents, employers, teachers, and religious or community leaders; and also to strangers, are recognized through formal and informal education

Table 6. Summary of two-way ANOVA of the main and interaction effects of EQ total and scales across countries and gender groups.

\begin{tabular}{cccccccccccc}
\hline & \multicolumn{9}{c}{ Main Effect } & \multicolumn{3}{c}{ Interaction Effect } \\
\hline \multirow{2}{*}{ EQ Total \& Scales } & \multicolumn{3}{c}{ Countries } & \multicolumn{3}{c}{ Gender } & \multicolumn{3}{c}{ Countries $\times$ Gender } \\
\hline & $F(1,2725)$ & $p$ & Effect Size $\left(\eta^{2}\right)$ & $F(1,2725)$ & $p$ & Effect Size $\left(\eta^{2}\right)$ & $F(1,2725)$ & $p$ & Effect Size $\left(\eta^{2}\right)$ \\
\hline Intrapersonal & $564.27^{*}$ & 0.00 & 0.17 & $6.31^{*}$ & 0.01 & 0.00 & $33.40^{*}$ & 0.00 & 0.01 \\
Interpersonal & $409.38^{*}$ & 0.00 & 0.13 & $77.37^{*}$ & 0.00 & 0.03 & $12.72^{*}$ & 0.00 & 0.01 \\
Adaptability & $650.20^{*}$ & 0.00 & 0.19 & $5.45^{*}$ & 0.02 & 0.00 & $29.71^{*}$ & 0.00 & 0.01 \\
Stress Management & $537.49^{*}$ & 0.00 & 0.17 & 0.33 & 0.56 & 0.00 & $62.03^{*}$ & 0.00 & 0.02 \\
General Mood & $346.39^{*}$ & 0.00 & 0.11 & $5.23^{*}$ & 0.02 & 0.00 & $13.53^{*}$ & 0.00 & 0.01 \\
Total EQ & $772.75^{*}$ & 0.00 & 0.22 & $15.45^{*}$ & 0.00 & 0.01 & $24.24 *$ & 0.00 & 0.01 \\
\hline
\end{tabular}

*. The mean difference is significant at the 0.05 level. 
Table 7. Summary of two-way ANOVA of the main and interaction effects of EQ sub-scales across countries and gender groups.

\begin{tabular}{|c|c|c|c|c|c|c|c|c|c|}
\hline \multirow{3}{*}{ EQ Sub Scales } & \multicolumn{6}{|c|}{ Main Effect } & \multirow{2}{*}{\multicolumn{3}{|c|}{$\begin{array}{c}\text { Interaction Effect } \\
\text { Countries } \times \text { Gender }\end{array}$}} \\
\hline & \multicolumn{3}{|c|}{ Countries } & \multicolumn{3}{|c|}{ Gender } & & & \\
\hline & $F(1,2725)$ & $p$ & Effect Size $\left(\eta^{2}\right)$ & $F(1,2725)$ & $p$ & Effect Size $\left(\eta^{2}\right)$ & $F(1,2725)$ & $p$ & Effect Size $\left(\eta^{2}\right)$ \\
\hline ES & $47.66^{*}$ & 0.00 & 0.02 & $52.58 *$ & 0.00 & 0.02 & 0.27 & 0.61 & 0.00 \\
\hline AS & 341.63* & 0.00 & 0.11 & 0.16 & 0.69 & 0.00 & $16.20^{*}$ & 0.00 & 0.01 \\
\hline SR & 163.58* & 0.00 & 0.06 & $6.22 *$ & 0.01 & 0.00 & $42.70^{*}$ & 0.00 & 0.02 \\
\hline SA & $792.41^{*}$ & 0.00 & 0.21 & $18.85^{*}$ & 0.00 & 0.01 & $12.94 *$ & 0.00 & 0.01 \\
\hline IN & 718.53* & 0.00 & 0.21 & 1.01 & 0.31 & 0.00 & 67.60 & 0.00 & 0.02 \\
\hline EM & $330.20^{*}$ & 0.00 & 0.11 & $42.87 *$ & 0.00 & 0.02 & $44.33^{*}$ & 0.00 & 0.02 \\
\hline $\mathrm{RE}$ & 501.18* & 0.00 & 0.16 & $55.49 *$ & 0.00 & 0.02 & $27.24 *$ & 0.00 & 0.01 \\
\hline IR & $115.55^{*}$ & 0.00 & 0.04 & $51.85^{*}$ & 0.00 & 0.02 & 0.75 & 0.39 & 0.00 \\
\hline PS & $29.22 *$ & 0.00 & 0.01 & $16.79 *$ & 0.00 & 0.01 & $25.88^{*}$ & 0.00 & 0.01 \\
\hline $\mathrm{RT}$ & $1175.90^{*}$ & 0.00 & 0.30 & $25.18^{*}$ & 0.00 & 0.01 & $16.47^{*}$ & 0.00 & 0.01 \\
\hline FL & $239.88^{*}$ & 0.00 & 0.08 & $9.47^{*}$ & 0.00 & 0.00 & $14.38^{*}$ & 0.00 & 0.01 \\
\hline ST & $120.05^{*}$ & 0.00 & 0.04 & $18.91^{*}$ & 0.00 & 0.01 & $60.36 *$ & 0.00 & 0.02 \\
\hline IC & $604.87 *$ & 0.00 & 0.18 & $16.54^{*}$ & 0.00 & 0.01 & $28.41^{*}$ & 0.00 & 0.01 \\
\hline HA & $774.62 *$ & 0.00 & 0.22 & $30.18^{*}$ & 0.00 & 0.01 & $13.32 *$ & 0.00 & 0.01 \\
\hline $\mathrm{OP}$ & 0.70 & 0.40 & 0.00 & $8.75^{*}$ & 0.00 & 0.00 & $5.68 *$ & 0.02 & 0.00 \\
\hline
\end{tabular}

*.The mean difference is significant at the .05 level. Note: EQ-i Abbreviations: ES = Emotional Self-Awareness; AS = Assertiveness; SR = SelfRegard; SA = Self-Actualization; IN = Independence; EM = Empathy; IR = Interpersonal Relationship; RE = Social Responsibility; PS = Problem Solving; RT = Reality Testing; FL = Flexibility; ST = Stress Tolerance; IC = Impulse Control; HA = Happiness; OP = Optimism (BarOn, 2004b).

from childhood (Koentjaraningrat, 2002; Setiadi, Supratiknya, Lonner, \& Poortinga, 2004). We consider that these values may be embodied in Indonesians' behavior styles and become a general characteristic of Indonesians society. Indonesians, to some extent, may be more skilled in social interaction with close persons in the neighborhood than in formal relationships. In such formal situations, Indonesian people may feel reluctant to deal with others. They tend to be shy, hesitant, or wary while Westerners are, to some extent, more confident. This fact seems relevant to a previous study on the profile of NEO PI-R in Indonesians, in which Indonesian people scored low in extraversion, values, and competence (Halim et al., 2004).

By performing comparison analyses between countries and gender groups, this study focuses attention on a wider range of Indonesian people instead of a specific group of the community, such as group of ethnics, persons with a specific disease/disorder, or professions. We consider the EI, as a trainable intelligence (BarOn \& Parker, 2000; BarOn, 2004a), could be linked to the positive psychology which focuses on potentials and well-being of any individuals. The illustration of the EI development of the Indonesians compared to the Dutch (see Result section and Figure 1) showed the importance of developing EI competences as one of Indonesians' potentials. For example, Indonesians could be trained to be more assertive, independent, and socially responsible in line with internalized social norms and values as an Indonesian. We think it is possible as now many Indonesian people, especially the middle and young generations, who live in big and small cities, become modern societies who have a modern life style in the meaning of their way of thinking. They are more flexible and open to learn and accept any information and knowledge through their interaction with people from other countries. We expect the more practical application through prevention and intervention programs would, in some ways, contribute to the development of Indonesians' quality in terms of emotional and social competences. A wide application of EI in various life settings in Indonesia, such as educational, workplace, and health, might also contribute to the improvements of EI concept and its application in cultural context.

The EI profile of the Indonesian and of the Dutch as shown in this study expectantly could illustrate a possible role of cultural values to the development of behavior styles. We found potential contribution of the contrast 
between collectivism versus individualism in generating different EI profiles of the Indonesians and the Dutch. To know to what extent the contribution of cultural value to the EI development, we recommend a wider cross-country research in the future.

\section{Conclusion}

Altough the criticism of the conceptualization and measurement of EI still continues to this day (Ashkanasy \& Daus, 2005), we believe that more studies on EI will make a valuable contribution to the development of the EI concept. Supported by scientific literature and previous studies, we expect that this study can contribute to the development of EI in terms of conceptual and practical issues. We also consider the importance of a crossnational EI study in the future in which more countries will be encouraged to participate in the study. It possibly contribute to draw a more globally and a wider conclusion about EI concept and application. Some previous studies that were being participated by tens countries (House, Hanges, Javidan, Dorfman, \& Gupta, 2004; Chhokar, Brodbeck, \& House, 2007) can be used as a good reference to conduct a cross-national study on EI later.

Various limitations should be noted. First, it is not known to what extent these results can be replicated in other more culturally diverse and multilingual societies. The investigation of the language invariance of the translated versions of the EQ-i compared to the original version from "home" country, Canada-USA, where the instrument was developed would, we think, will be valuable. Second, generalization about the EI competences of Indonesians cannot be made only based on the study in the west area of Indonesia. The future studies on the middle and east areas of Indonesia expectantly could give a stronger contribution to the EI concept and its application in Indonesian society. Furthermore, the intervention programs of EI development in Indonesians would be more appropriate and reliable after we provide a portrayal of EI development in a wider Indonesian society later. Third, age is another factor in examining the development of EI competences. We think, future study on EI that explicitly includes age as a variable to be tested expectantly could give a stronger contribution to the EI concept and its appliance.

\section{Acknowledgements}

We are grateful to Michael Alan Holliday for his support as our English proof-reader.

\section{References}

Alisjahbana, S. T. (1989). The Concept of Culture and Civilization: Problems of National Identity and the Emerging World in Anthropology and Sociology. Jakarta: Dian Rakyat.

Ashkanasy, N. M., \& Daus, C. S. (2005). Rumors of the Death of Emotional Intelligence in Organizational Behavior Are Vastly Exaggerated. Journal of Organizational Behavior, 26, 441-452. http://dx.doi.org/10.1002/job.320

BarOn, R. (1997). BarOn Emotional Quotion-Inventory. http://www.mhs.com

BarOn, R. (2004a). The Bar-On Emotional Quotient Inventory (EQ-i): Rationale, Description, and Summary of Psychometric Properties. In G. Geher (Ed.), Measuring Emotional Intelligence: Common Ground and Controversy (pp. 111-142). Hauppauge, NY: Nova Science Publishers.

BarOn, R. (2004b). BarOn Emotional Quotient Inventor, a Measure of Emotional Intelligence: Technical Manual. Toronto: Multi-Health System Inc.

BarOn, R., \& Parker, J. D. A. (2000). The Handbook of Emotional Intelligence: Theory, Development, Assessment, and Application At Home, School, and in the Workplace. San Francisco, CA: Jossey-Bass, A Wiley Company.

Berry, J. W., Poortinga, Y. H., Segall, M. H., \& Dasen, P. R. (2002). Cross-Cultural Psychology: Research and Applications (2nd ed.). Cambridge, UK: Cambridge University Press.

CDC-Atlanta. (2014). CDC in Indonesia. http://www.cdc.gov/globalhealth/countries/indonesia/

Chhokar, J. S., Brodbeck, F. C., \& House, R. J. (2007). Culture and Leadership across the World: A GLOBE Report of In-Depth Studies of the Cultures of 25 Countries. Mahwah, NJ: Lawrence Erlbaum Associates.

Ciarrochi, J., Forgas, J. P., \& Mayer, J. D. (2001). Emotional Intelligence in Everyday Life: A Scientific Inquiry. Taylor \& Francis.

Cohen, J. (1988). Statistical Power Analysis for the Behavioral Sciences (2nd ed.). Mahwah, NJ: Lawrence Erlbaum Associates.

Depkes, R. I. (2006). Pharmaceutical Care untuk Pasien Penyakit Jantung Koroner: Fokus Sindrom Koroner Akut (Phar- 
maceutical Care for Patients of Coronary Heart Disease: Focus on Acute Coronary Syndrome). Jakarta: Depkes RI.

Derksen, J. (2007). Zijn wij wel narcistische genoeg? Over het ontstaan van onze lentecultuur als gevolg van gewijzigde vroegkinderlijke condities (Are We Enough?) Nijmegen: PEN Tests Publisher.

Derksen, J., Kramer, I., \& Katzko, M. (2002). Does a Self-Report Measure for Emotional Intelligence Assess Something Different than General Intelligence? Personality and Individual Differences, 32, 37-48. http://dx.doi.org/10.1016/S0191-8869(01)00004-6

Dusseldorp, L. R. L. C., van Meijel, B. K. G., \& Derksen, J. J. L. (2011). Emotional Intelligence of Mental Health Nurses. Journal of Clinical Nursing, 30, 555-562. http://dx.doi.org/10.1111/j.1365-2702.2009.03120.x

Ekermans, G., Saklofske, D. H., Austin, E., \& Stough, C. (2011). Measurement Invariance and Differential Item Functioning of the Bar-On EQ-i: S Measure over Canadian, Scottish, South African and Australian Samples. Personality and Individual Differences, 50, 286-290. http://dx.doi.org/10.1016/j.paid.2010.10.004

Fjneman, Y. A., Willemsen, M. E., Poortinga, Y. H., Erelcin, F. G., Georgas, J., Hui, C. H., Leung, K., Roy, S., \& Malpass, R. S. (1996). Individualism-Collectivism: An Empirical Study of a Conceptual Issue. Journal of Cross-Cultural Psychology, 27, 381-402. http://dx.doi.org/10.1177/0022022196274001

Gardiner, H. W., \& Kosmitzki, C. (2005). Lives across Cultures: Cross-Cultural Human Development (3rd ed.). Boston, MA: Pearson Education, Inc.

Gerits, L., Derksen, J. J. L., \& Verbruggen, A. B. (2004). Emotional Intelligence and Adaptive Success of Nurses Caring for People with Mental Retardation and Severe Behavior Problems. Mental Retardation, 42, 106-121. http://dx.doi.org/10.1352/0047-6765(2004)42<106:EIAASO>2.0.CO;2

Gerits, L., Derksen, J. J. L., Verbruggen, A. B., \& Katzko, M. (2005). Emotional Intelligence Profiles of Nurses Caring for People with Severe Behaviour Problems. Personality and Individual Differences, 38, 33-43.

http://dx.doi.org/10.1016/j.paid.2004.03.019

Halim, M. S., Derksen, J. J. L., \& van der Staak, C. P. F. (2004). Development of the Revised NEO Personality Inventory for Indonesia: A Preliminary Study. In B. N. Setiadi, A. Supratiknya, W. J. Lonner, \& Y. H. Poortinga (Eds.), Ongoing Themes in Psychology and Culture (Online Ed.). Melbourne, FL: International Association for Cross-Cultural Psychology. http://www.iaccp.org

House, R. J., Hanges, P. J., Javidan, M., Dorfman, P. W., \& Gupta, V. (2004). Culture, Leadership, and Organizations: The GLOBE Study of 62 Societies. Thousand Oaks, CA: Sage Publications.

Kitayama, S., \& Markus, H. R. (1994). Emotion and Culture: Empirical Studies of Mutual Influence. Washington DC: American Psychological Association. http://dx.doi.org/10.1037/10152-000

Koentjaraningrat. (2002). Manusia dan kebudayaan di Indonesia (Humans and Culture in Indonesia). Jakarta: Djambatan.

Li, T., Saklofske, D. H., Bowden, S. C., Yan, G., \& Fung, T. S. (2012). The Measurement Invariance of the Wong and Law Emotional Intelligence Scale (WLEIS) across Three Chinese University Student Groups from Canada and China. Journal of Psychoeducational Assessment, 30, 439-452. http://dx.doi.org/10.1177/0734282912449449

Matsumoto, D. (1984). People: Psychology from a Cultural Perspective. Belmont, CL: Brooks/Cole Publishing Company.

Parker, J. D. A., Saklofske, D. H., Shaughnessy, P. A., Huang, S. H. S., Wood, L. M., \& Eastabrook, J. M. (2005). Generalizability of the Emotional Intelligence Construct: A Cross-Cultural Study of North American Aboriginal Youth. Personality and Individual Differences, 39, 215-227. http://dx.doi.org/10.1016/j.paid.2005.01.008

Schulze, R., \& Roberts, R. D. (2005). Emotional Intelligence: An International Handbook. Gottingen: Hogrefe \& Huber Publishers.

Setiadi, B. N., Supratiknya, A., Lonner, W. J., \& Poortinga, Y. H. (2004). Ongoing Themes in Psychology and Culture. Melbourne, FL: The International Association for Cross-Cultural Psychology.

Stough, C., Saklofske, D. H., \& Parker, J. D. A. (2009). Assessing Emotional Intelligence: Theory, Research, and Application. New York: Springer.

Van Dierendonck, D., Rodríguez-Carvajal, R., Moreno-Jiménez, B., Maria T. M., \& Dijkstra, M. T. M. (2009). Goal Integration and Well-Being: Self-Regulation through Inner Resources in the Netherlands and Spain. Journal of Cross-Cultural Psychology, 40, 746-760. http://dx.doi.org/10.1177/0022022109338622

Wood, L. M., Parker, J. D. A., \& Keefer, K. V. (2009). Assessing Emotional Intelligence: Using the Emotional Quotient Inventory (EQ-i) and Related Instruments. In C. Stough, D. H. Saklofske, \& J. D. A. Parker (Eds.), Assessing Emotional Intelligence: Theory, Research, and Applications (pp. 67-84). New York: Springer Science + Business Media, LLC.

World Health Organization, WHO. (2013). World Health Statictics 2013.

http://www.who.int/gho/publications/world_health_statistics/ 